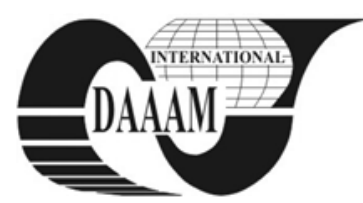

Annals of DAAAM for 2012 \& Proceedings of the 23rd International DAAAM Symposium, Volume 23, No.1, ISSN 2304-1382 ISBN 978-3-901509-91-9, CDROM version, Ed. B. Katalinic, Published by DAAAM International, Vienna, Austria, EU, 2012 Make Harmony between Technology and Nature, and Your Mind will Fly Free as a Bird Annals \& Proceedings of DAAAM International 2012

\title{
INTEGRATING ADAPTRONICS IN INTELLIGENT MEASUREMENT TECHNIQUE AND IN MECHATRONICS AND INTEGRONICS SYSTEMS FOR INTEGRATED CONTROL
}

\author{
GHEORGHE, I[on] G[heorghe]; ISTRITEANU, S[imona] - E[lena]; \\ CONSTANTINESCU, A[lexandru] \& DESPA, V[eronica]
}

\begin{abstract}
The paper presents hard and software architecture of adaptonics in intelligent measurement engineering and in mechatronics and integronics systems for integrated automatic control, through cooperation between several scientific and technical disciplines, to meet growing and changing demands about modern systems and new products simultaneously improved with the lowest development time and with a higher flexibility and more efficient.
\end{abstract}

Keywords: adaptronics, intelligent measurement engineering, mechatronics and integronics systems, integrated automated control

\section{INTRODUCTION}

Integrating Adaptronics in intelligent measurement engineering and mechatronics and integronics systems of integrated, automated control, actually describes the vanguard of high-tech advanced domain, that supports intensive transfer of technology and products, ensuring thus implementing innovating technology intelligent in industrial and operational domains that conduct to economical growth and higher level of labour force. That integration, partially or complete of adaptronics, creates new design of mechatronics systems, integronics and adaptronics for the improvement of performances for the products and extinsed profile of high-tech systems and simultaneously for a minimum time of development and a higher flexibility.

\section{INTELLIGENT FUNCTIONAL AND APPLICATIVE STRUCTURE FOR APPLICATIVE INDUSTRIAL AND COMMERCIAL SENSORICS AND MICRO- NANO-SENSORICS}

High-tech "sensoric and micro-nano-sensoric Adaptronics" was developed and modernized according both to developments in technology and especially to new discoveries of intelligent advanced materials that have enabled their use in sensors and micro-nano-sensors construction with high performance and intelligent human-like functions [1]. "Sensoric and micro-nanosensoric Adaptronics" is synthesized structurallytechnologically and intergrativelly in Figure 1. Consequently, according to the mentioned figure: the integrative structural architecture for sensoric and micronano-sensoric. Adaptronics is synthesized through synergy and combination of the sub-domains of sensitive elements and components (capacitive, magnetic, piezoelectric, photoelectric, interferomeric, telemetric, ultrasonic, elements and components and so on) mechanical elements, components and parts (guides, springs, links, elements, pneumatic, hydraulic components and parts and electronic components and parts (integrated circuits, digital components, amplifiers, comparators, dividers, interfaces, counters, drives, transformers, oscillators, and so on.) actuator elements and components, elements and assemblies for sensors, computing elements and components (processors, controllers, integrators, informatic units, computers, and so on.). The intelligent integrating science assembles mix innovative constructive and technological solutions and mix adaptive innovative solutions and mix innovative hardware and software technologies with advanced adaptive hardware and software solutions with intelligent manufacturing technologies and intelligent manufacturing micro-nanotechnologies and advanced intelligent materials and advanced intelligent micro-nano materials [2]; the results of the field of ,sensoric and micro-nano-sensoric Adaptronics" are materialized in intelligent adaptronic micro-sensors and nano-sensors intended for intelligent strategic priority areas; the products and technologies are applied in many current and prospective areas.

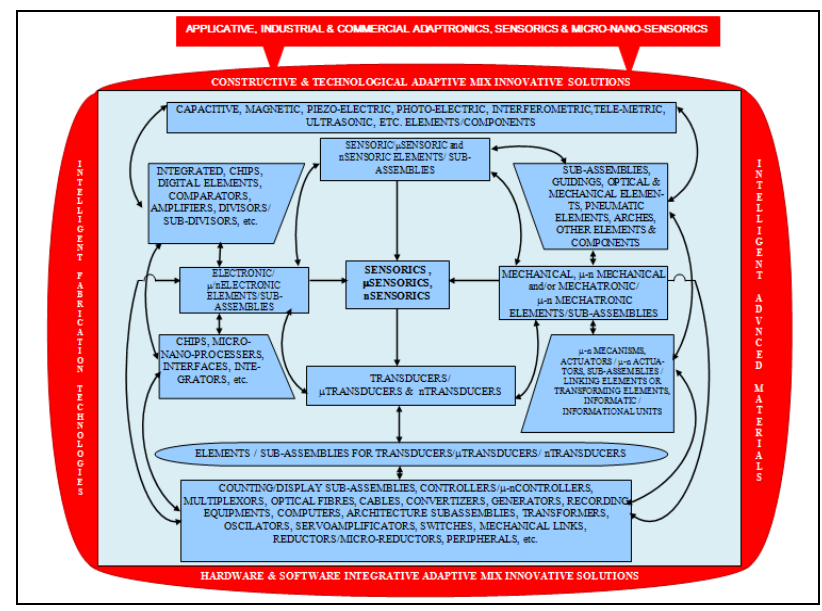

Fig. 1. Sensoric and micro-nano-sensoric Adaptronics

3. Intelligent functional and applicative structure for Adaptronics, integrative mechatronics, adaptronics integrative to the human being

The high-tech field of "Adaptronics, integrative mechatronics, adaptronics integrative " has been approached for a little while, but it has been developed with intensity, both for expansion and rich diversification, and especially for intelligent and hyperintelligent applications in the service of man and 
integrating to himself, in human skills in different mental environments and intelligent man-machine combination.

Currently, there is a great interest in the development of this field mainly through the application and implementation of integrative adaptronic mechatronic micro-mechanisms and micro-nano-systems adaptive to the human being and simmilar to those in the biological world, for an excellent education and training.

Moreover, this high-tech field, can be considered as a "new integronic vision on new technological product" by integrating hardware and software that facilitates unexpected scientific horizons in all areas and calling for its synergistic effect [3].

The permanent development and modernization of human-intelligent machine interfaces and mechatronic and integronic multi-functional intelligent structures in a relationship and adaptation to the new conditions and requirements, but especially according to the new technologies and intelligent materials, have contributed to the "concept and product or mechatronic integrator system adaptive to the human being" (fig. 2).

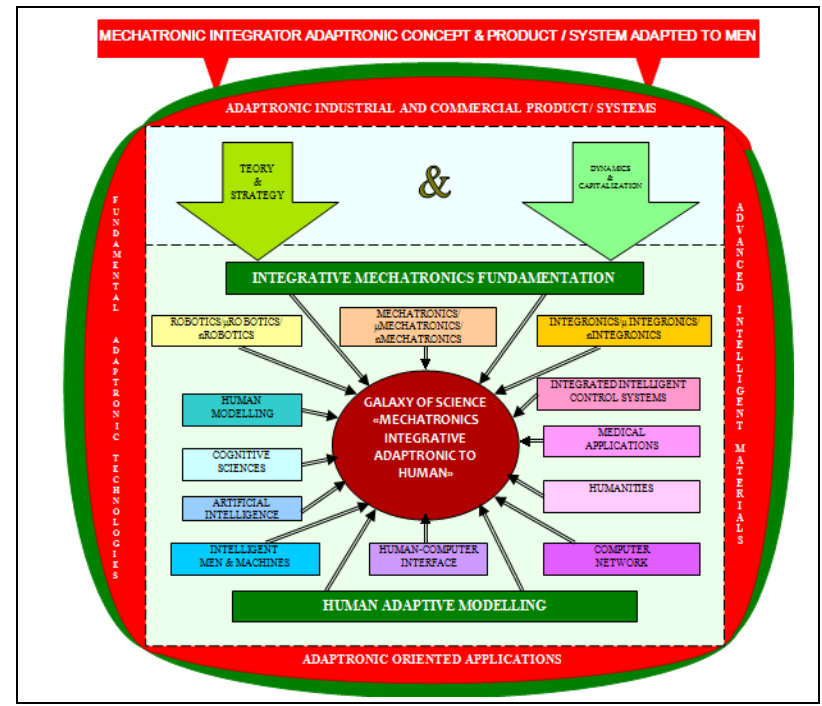

Fig. 2. Mechatronic integrator system adaptive to the human being

Consequently, according to the Figure: mechatronic integrator adaptive to the human being concept and product / system are synthesized by a mix - matrix structure and synergy of theoretical, fundamental, constructive and strategic sub-fields: mechatronics, in its "ensemble and expansion" of " science galaxy " (including micro-nano-mechatronics), robotics (including micro-nano-robotics) and integronics (including micronano-integronics) - as advanced high-tech sub-fields; integration and adaptation process, in order to create and develop constructive and functional structure, the hightech area, call the combination of techniques and technologies and to meet new conditions and new applications to obtain solutions, effects and impact, such as: integrated intelligent control systems, computer networking, artificial intelligence, human modeling, human-computer interfaces, intelligent human-machine systems, and so on; human adaptive integration, interrelate with cognitive and human sciences for dynamism and enhance human adaptive modeling steps and adaptronic processes and applications, in order to build these adaptronic processes and applications serving human environment, is assembled, to the whole system so advanced high technologies and smart materials - all structural and multifunctional properties, to achieve specific results, with industrial and commercial applications, in human area; these results are embodied in products and human adaptive mechatronic integrator adaptronic systems that are targeted by theoretical decisions and strategic directions, immediate and future valuation in dynamic trends stages and corresponding human needs and care [4].

This permanent development of the integrative adaptronic mechatronic concept and products or systems adapted to the human being, ensures in fact and in perspective the intelligent logistic for enhancing and monitoring the informational society from the point of view of quality, security and social status, according to national, European and international norms, regulations and standards.

This new advanced high-tech field "Integrating Adaptronic Mechatronic Integronics adapted to the human being", in the architectural, complex, mix and intelligent process, ensures in a perceptible and objective manner the flexibility and adaptability in action [5], thought and application, by developing of systemic logistics and judgment and by the skills needed to work in a team.

The adaptronic concepts of the advanced high-tech field enclose mainly and in synthesis:

a. Multidisciplinary combination of intelligence and integrated control, in the ensemble of the system;

b. Basic applications, in the medical, engineering, diagnosis, disaster rescue, human supporting services, and so on;

c. Highly advanced intelligent and hyper-intelligent knowledge and so on

\section{EXAMPLES OF STUCTURAL ADAPTRONIC SYSTEMS REALISED IN THE NATIONAL INSTITUTE FOR RESEARCH AND DEVELOPMENT FOR MECAHTRONICS AND MEASUREMENT TECHNIQUE BUCHAREST-ROMANIA}

\subsection{Adaptronic systems flexible of intelligent measurement for molded parts integrated in manufcaturing technology automotive intelligent: \\ For tightness checking of distribution chankase, types: $H 4 B t 8^{\circ}, H 4 D A 49^{\circ}, H 4 B t 49^{\circ}$ Sulev (fig. 3)}

The testing unit is a complex, mono-block construction use in checking tightness of the pieces type distribution crankase. All the moving subassemblies are operated by pneumatic cylinders assisted by a lot of proximities sensors. The piece is tightening on both sides. The ATEQ-cell is provided with 2 circuits and realizes the measurement cycle after the fixation and tightening of distribution crankcase

Technical and functional features: 
- electrical supply: 220 V.c.a./50 Hz;

- pressure supply: min. 6 bar;

- work pressure: 5 bar;

- tightness test pressure: 1 bar, on both cycles;

- admissible air loss:

- $3,6 \mathrm{~cm}^{3} / \mathrm{min}$ on low pressure cycle;

- $12 \mathrm{~cm}^{3} / \mathrm{min}$ on high pressure cycle ;

- cycle time: $~ 40 \mathrm{sec} /$ piece.

Applicability, capitalization and technology transfer The product is delivered and implemented on the production line of distribution crankase, types: $\mathrm{H} 4 \mathrm{Bt} 8^{\circ}$, H4DA49 ${ }^{\circ}, \mathrm{H} 4 \mathrm{Bt} 49^{\circ}, \mathrm{H} 4 \mathrm{Bt} 49^{\circ}$ Sulev at SC Automobile Dacia SA Mioveni.

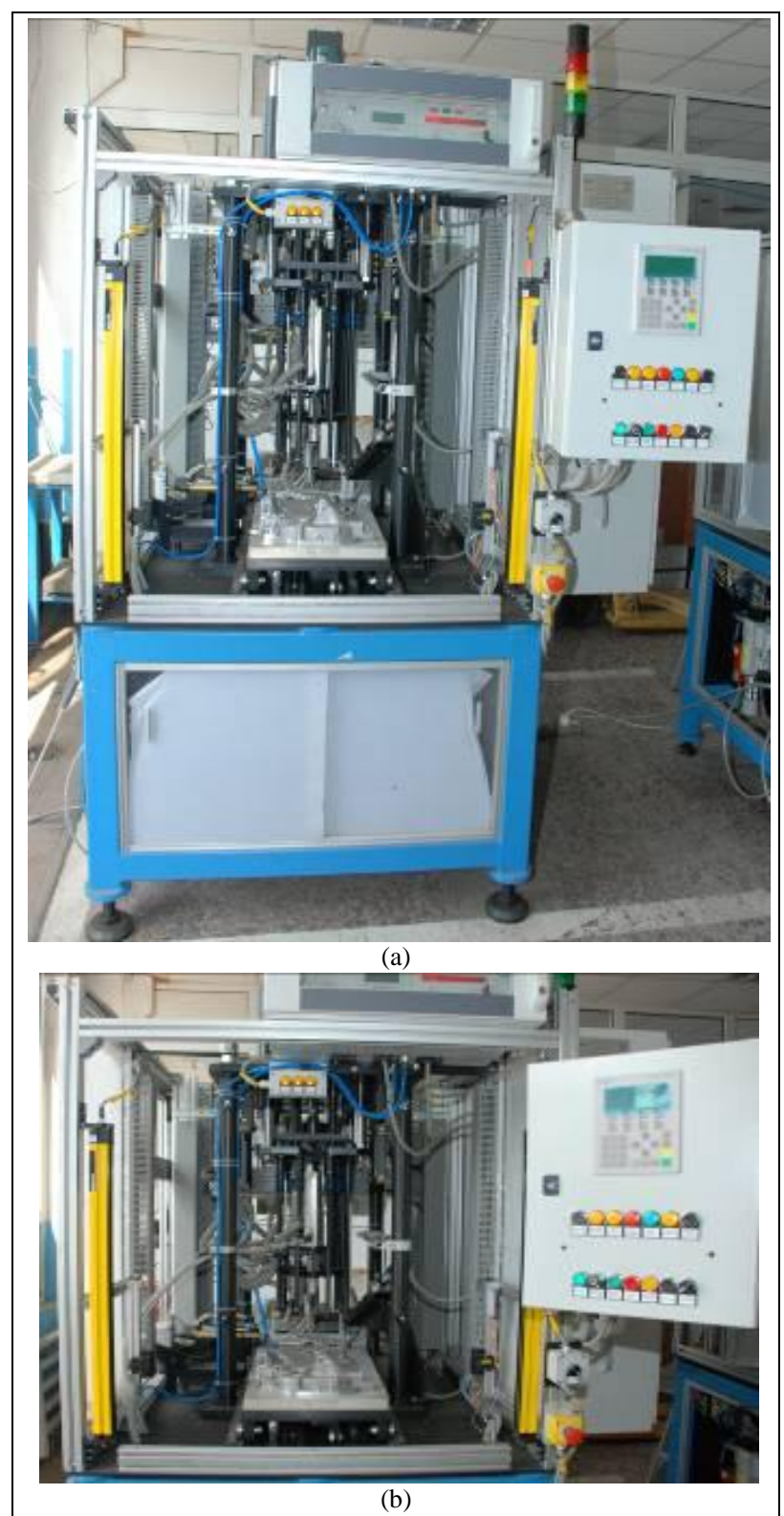

Fig. 3. (a, b) Adaptronics equipment for intelligent measurement for the tightness checking of distribution crankcase

4.2. Adaptronics equipment for intelliogent measurement for tightness cheking (air) cylinder head bonnet- machined types: $\mathrm{H}_{4 \mathrm{Bt}}{ }^{\circ}, \mathrm{H}_{4 \mathrm{DA}} 49^{\circ}$, H4Bt49 ${ }^{\circ}, \mathrm{H} \mathrm{Bt} 49^{\circ}$ Sulev (fig. 4)

The testing unit is a complex, mono-block construction use in checking tightness of the pieces type
Cylinder Head. All the moving subassemblies are operated by pneumatic cylinders assisted by a lot of proximities sensors. The piece is tightening on both sides. The ATEQ-cell is provided with 2 circuits and realizes the measurement cycle after the fixation and tightening of the Cylinder Head Bonnet.

Technical and functional features:

- electrical supply: 220 V.c.a./50 Hz;

- pressure supply: min. 6 bar;

- work pressure: 5 bar;

- tightness test pressure: 1 bar;

- admissible air loss: $25 \mathrm{~cm}^{3} / \mathrm{min}$

- cycle time: $\sim 40 \mathrm{sec} /$ piece.
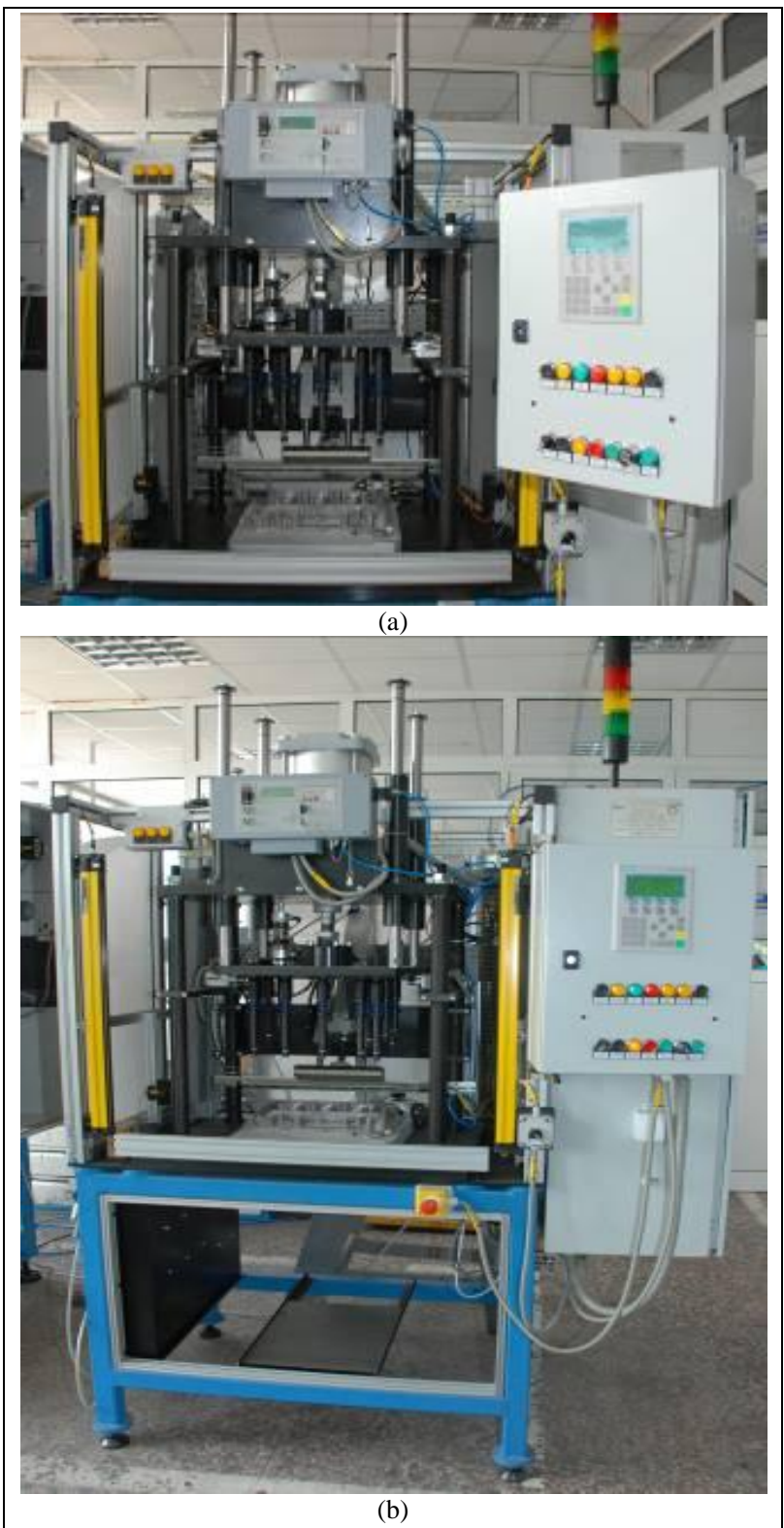

Fig. 4 (a, b) Adaptronics equipment for intelligent measurement for tightness cheking (air) cylinder head bonnet

Applicability, capitalization and technology transfer benefficiary. The product is delivered and implemented on the production line of Cylinder Head BonnetMachined, Types: $\mathrm{H}_{4 \mathrm{Bt}}{ }^{\circ}$, H4DA49 ${ }^{\circ}$ H4Bt49 ${ }^{\circ}$, $\mathrm{H} 4 \mathrm{Bt} 49^{\circ}$ Sulev at SC Automobile Dacia SA Mioveni. 


\subsection{Flexible adaptronics system for micro- measurement and micro-positioning for industrial micro-platform}

Flexible adaptronics system for micro-measurement and micro-positioning for industrial micro-platform (fig. 5) was designed and realised for integration in the follows applications: precisional positioning for measurement; surface characterization in vectorial complex space and temperature; intelligent mechatronic system to determinate measurement of global constant for optical systems with complex software algoritms; calibration system of inductive sensors.

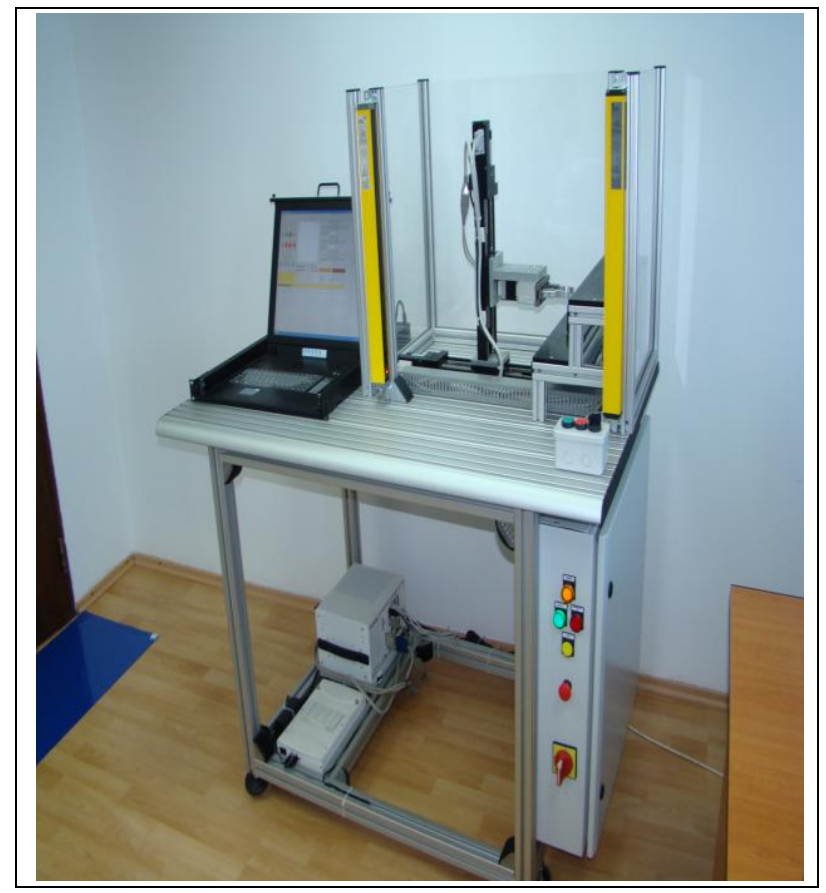

Fig. 5. Flexible adaptronics system for micro-measurement and micropositioning for industrial micro-platform

Technical and functional features:

- measuring range: $x=200 \mathrm{~mm} ; z=200 \mathrm{~mm}$

- resolution: $0,00005 \mathrm{~nm}$;

- accuracy: $\pm 0,00025 \mathrm{~nm}$;

- fidelity: $\pm 0,00015 \mathrm{~nm}$;

- transport task: $\mathrm{x} \rightarrow 100 \div 200 \mathrm{~N} ; \mathrm{z} \rightarrow 25 \div 50 \mathrm{~N}$;

- mass : $500 \mathrm{~g}$

- load-download : automated.

Realised tests were intented to set off the operating parameters for components of flexible mechatronic systems for positioning, to realise components characterization of system from constructive point of view, functional precision and exploitation reliability.

Obtaining and implementation of functional parameters of microsystem components allows : obtaining of minimal technologic track, realised by application of a original concept generated by flexible usage possibilities; utilising of a robust gripper, able to provide required stiffness to develop a clamping force sufficient to defeat semifinished inertia during transport ; ensuring higher precision for part positioning; elaborating of adequately software programm, structured in relation to functions of each component model of system.

\section{FUTURE RESEARCH PLANS}

Based on present research results from this paper, future research plans in adaptronic domain, include :a) creation, development, maturation of new adaptronic solutions and specific to other adaptronic systems and micro-nano mechatronics integronics adaptronic systems, specific to advanced domains of tribological characterization, to obtain new performances of metallic layers, made by selective sintering with lasers and applications in prosthetic engineering; b) creation, implementation and development of new mix-innovative mechatronics, integronics, adaptronics solutions, specific to advanced metrological micro-nano metrics domains, to obtain new ultraprecise characteristics in the measurement and intelligent control processes from intelligent manufacturing, The steps in this adaptronic researches include : experiments of new theoretical and proactive approaches, defining and identifying of innovative adaptronics mix-sollutions, design, development and implementation of new mechatronics, adaptronics systems.

\section{CONCLUSION}

Adaptronics in a quality of concept for the development of the structures and adaptronic systems, apply the technological and innovative research in the fields of multifunctional and multistructural materials and elements and in the field of materials systems, intelligent which have the characteristics like human beans, with the scope of reducing total mass and energy and for producing an adaptive functionality and anticipative, in accordance with description of anatomy adaptronic systems (actuators or engines that will be utilise like muscles, sensors that functions like the five senses: smell,hearing, sight, tactil, taste) and communication and PC networks which represents nervs systems, brain, memory and system of muscular control. The adaptronic approach borrow directly from biological humans and adaptronic structures represents complex systems which can take place movement functions, sensorics and artificial intelligence, all in a synergetic mode.

\section{REFERENCES}

[1] Dhillon, G, S, Horch, K. W (2005). Dirrect neural sensory feedback and control of a prosthetic arm IEEE Trans Neural Sys Rehabil. Eng. 13(4) pp. 468-472

[2] Gheorghe, G et al.(2004). Microsensorics, micromechatronics and microrobotics. Cefin Publishing House, Romania

[3] Giurgiutiu, V., Lyshevski, S.E (2004). Micromechatronics. Modeling, Analysis and Design with MATLAB, CRC Press, ISBN 084931593X

[4] Lago, N., Ceballos D, Rodrigues, F. J., Stieglitz, T., Navarro, X (2005). Long term assessment of axonal regeneration through polimide regenerative electrodes to interface the peripheral nerve. Biomaterials, 26, pp 2021-2031

[5] Walter, R, Kiswiday. Z, F, Gortz, M, Alteheld, N, Rossler, G, Stieglitz, T, Eysel, U. T (2005). Cortical activation with a completely impanted wireless retinal prostheses. Investigative oftalmology and visual science vol. 46, no. 5, pp. 1780-1785 